\title{
The Effect of a Computerized Program on Tenth Grade Students' Acquisition of English Vocabulary
}

\author{
Atef Ali Jaradat \\ Yarmouk University, Irbid, Jordan
}

\author{
Fawwaz Al-Abed Al-Haq \\ Vice President of Tafila University, Tafilah, Jordan
}

\begin{abstract}
This study investigated the effect of a computerized program on tenth grade students' acquisition of English vocabulary. The study also examined if computer games stimulate and motivate EFL (English as a Foreign Language) learners to increase their vocabulary. Subject of the study were 150 students, drawn from Ali Khoulki Al-Sharari Secondary School for boys in Irbid the First Educational Directorate in the first semester of the academic year 2008/2009. A computerized program “Games" was used to measure students' acquisition of English vocabulary including four domains: conversation, synthesis, recall and preservation, and reading. Findings of the study revealed significant differences in means scores between experimental and control groups students, in favor of experimental group students, due to the instructional method used. Furthermore, students in the experimental group reported positive attitudes towards learning English vocabulary using computer games. Based on the findings of the study, the researcher suggested some recommendations and instructional implications.
\end{abstract}

Keywords: computerized program, vocabulary, acquisition

\section{Introduction}

English is an international language and fundamental to learning and communicating in all cultures. For Jordanian students, EFL curriculum should help the learners to internalize the Islamic and Arabic culture, which should be used as a spring board to understand, appreciate, and interact with people of different countries as well as Jordanian identity. With the increasing use of ICT (Information and Communication Technology), our students need to cope with different means of technology that emerge as a result. In addition, students may need to learn English if they seek to get a future career. Through learning English, they will be able to develop confidence, competence, and self-reliance to meet the demands of school employment and further education (Teacher's Magazine, Ministry of Education, Jordan, 2007).

Students need to acquire a sufficient knowledge of English that will enable them to utilize the ordinary and electronic libraries when doing their projects, reports, research papers, etc. To be able to express oneself in English, a student needs to show mastery over the four skills of language (i.e., listening, speaking, reading, and writing) in addition to appreciation of literature. HelShe can benefit from mass media such as newspapers, magazines, TV, and Internet; it is assumed that after learning English at school, students will have deepened their values and heritage; at the same time, they can cope with emerging issues analytically and critically. (Teacher's Magazine, MOE, 2007).

Atef Ali Jaradat, lecturer, M.A., Department of English Language, Yarmouk University, Irbid, Jordan.

Fawwaz Al-Abed Al-Haq, professor, Ph.D., Department of English Language, Vice President of Tafila University, Tafilah, Jordan. 
Understanding the specific nature of the relationship between educational games and simulation computer programs and how they affect learning is a critical issue in the educational field due to society's reliance on computers. Both children and adults are now being required to interact with computers in all settings, including educational ones. Schools, universities, and even job training setting recognize that computer programs are very effective in reducing educational and training costs (Reinking, 1996).

One might assume that teachers do not use computers because they require more effort by the teacher for little perceived cognitive gain. This is not intended to place blame on teachers for this situation. Rather, it is the job of researchers to find a way to help already overworked teachers by creating computer systems that reduce the children's time on task and increase their cognitive gains. Put differently, computer programs need to teach people better and faster (Solowlay, 1998).

Educational games are one of the oldest and simplest instructional methods used in the course of history. Coleman (1990) argued that educational games are vital for achieving instructional objectives. In the same vein, Coleman (1990) posited that instructional games are integral strategies that may be used to promote learner's language skills and mental growth.

As for the instructional process, Gardner (1998) pointed out that educational games play an essential role in the teaching process; they provide students with a secure environment while participating in the language skills tasks. Games equip teachers with the needed means to overcome the obstacles encountered during the teaching process. While adopting educational games, teachers pay special attention to individual differences among students. Amory and Adams (1999) pointed out that development of learning tools based on the computer adventure games could provide educators with a suspensor mechanism to persuade learners into virtual environments where knowledge is acquired through intrinsic motivation.

The use of language games requires that teachers plan in advance the steps to be followed in the instructional process. They are also to provide students with the necessary materials to carry out the learning task. Teachers must ensure that students have adequate prior knowledge and needed experiences which are the cornerstone in the class where the instructional games are used (Paz, 1993). Hubbard (1991) argued that instructional games are essentially means for stimulating communicative activities.

Educational games are both beneficial for teachers and students while discussing the benefits of educational games. Decure (1995) pointed out that the use of educational games is one of the most vital means for delivering the curriculum content for students. Teachers may use educational games to help students organize their thoughts during the learning activity. Kim (1995) argued that using educational games makes the learning process an enjoyable activity for students. Kim (1995) outlined a set of prerequisite conditions while using the educational games in language classroom activities:

(1) The goals of the games must be preplanned;

(2) The game must be suitable for student's age and mental ability;

(3) The game must motivate students to think, notice, observe, and compare;

(4) The time limit of the game must be set in advance;

(5) The game must be performed in the classroom.

On the other hand, Betz (1995) listed a variety of advantages for using computer games:

(1) Computer games are attention grabbing and attention holding;

(2) Computer games provoke interactivity and motivation among students; 
(3) Computer games facilitate interaction between a large numbers of people plying the game;

(4) Many people enjoy this kind of social interaction.

Computer games have the advantage of engaging students in activities designed to achieve the desired educational skills; they also have the advantage of helping students achieve targeted learning outcomes individually. Mumtaz (2001) and Nagy (1989) reported that learning via computers, audio books, and multimedia has positive effects on students' language skills.

Wishart and Blease (1989) noted that different types of software available allow the possibility of control of instruction to be varied from the computer to the learner, thus suiting a variety of individuals with different learning styles. Compute Assisted Instruction (CAI) is one of the most common applications for computer technologies in education. Hannafin and Peck (1988) pointed out that Compute Assisted Instruction (CAI) seeks to facilitate learning. The authors believe that in the traditional classrooms, teachers are unable to spend adequate time with individual students, in planning and development, grading, following up, and evaluating student's performance objectively. They also believe that computers have different advantages such as the ability to perform at high speed, collect and manage information, and motivate students to perform repetitive tasks without boredom.

Karsilnikov (1989) described the development of one of the courses in Russia using Compute Assisted Instruction (CAI) developed to deliver second-language reading skills. Nine computer programs, consisting of learning modules, were developed to address specific reading skills not likely to have been attained by the students at the level of second language literacy. The modules provided practice in word recognition and comprehension recognition of word boundaries, sentence structures recognition of the devices used to create textual cohesions sentence completion, vocabulary development skimming skills, and scanning and practice in reading for global understanding. While the effect of this particular program was not discussed, the creators of these modules emphasized the teaching of particular skills. In addition, the activities described appear to provide practice in both top-down and bottom-up reading comprehension strategies. From the researcher's point of view, the teachers assume the responsibility to find, examine, or apply the most effective instructional strategy to encourage students to select the new word and use different sources to attain new vocabulary books.

\section{Computer Programs}

A computer program is a set of sequential instructions that tell the computer what to do. Software is a collection of programs, data, and information. Hardware is the physical component (parts of the computer), while software represents the logical component and is concerned with thinking, knowledge, and planning. Software is mainly divided into two major kinds:

(1) System Software

It is the software which is used by the computer or operates a computer system such as: operating system, programming languages, and translators.

(2) Applications Software

It is the software used by users like word processors, spreadsheets, databases, e-mail programs, graphics and drawing programs, presentation tools, publishing software games, and multimedia programs (Collin, 1989).

\section{Statement of the Problem}

Several factors influence second language learning. These factors include mainly the social encouragement, nature of learning process, students' readiness, modern technology, and most importantly 
instructional method used. In Jordan, English is one of the most difficult school subjects for most students. Standardized tests, especially general secondary school certificate examination (AlTawjihi)-High Schoolresults have shown many students fail these standardized tests due to lack of proficiency in English (MOE, 2007). Finding the most appropriate and effective way to deliver English curricula was and is still one of the major challenges that English teachers and educators face. The researcher believes that teaching aids and techniques, especially computer have great influence on students' contact with educational materials in particular languages. The researcher attempts to examine the importance of computerized program in language learning, acquisition of English vocabulary, and its effects on achievement.

\section{Purpose of the Study}

The main purpose of this study is to evaluate the effect of a computerized program on tenth grade students' acquisition and development of their English vocabulary. Furthermore, it aims at improving the students' vocabulary pronunciation and writing and helps them to overcome the difficulties that face the EFL students.

\section{Objectives}

The specific objectives of the computerized game are the following. By the end of the program, students should be able to:

(1) Spell the words correctly;

(2) Recognize the words correctly;

(3) Improve the reading vocabulary skills;

(4) Memorize and retrieve words easily;

(5) Write the words correctly;

(6) Improve the listening skills.

\section{Questions of the Study}

This study aims to answer the following questions:

(1) Are there any significant differences $(\alpha=0.05)$ between the mean scores of students who learn English vocabulary using computer games and those who learn it using traditional method?

(2) To what extent do computer games stimulate and motivate EFL learners to increase their vocabulary?

\section{Hypothesis of the Study}

This study attempts to test the following hypothesis:

Computer programs (games) have a positive effect on the achievement of the tenth grade students.

\section{Significance of the Study}

The significance of the study stems from the topic addressed. As indicated in the statement of the problem of the study, English as a school subject is a main stressor for teachers, principals, students, and parents. This study is an attempt to motivate teachers and curriculum designers to adopt integrating games in English curriculum. The significance of this study came from the fact that it provides teachers with computer games which help them in teaching vocabulary to tenth grade students. Using some of the games, the learner can revise a massive amount of vocabulary in a few minutes. Computer online games longer the short attention span, so the teachers can keep the learners alert and enjoying themselves. Hopefully, the findings of the study will help teachers, instructors, and educational policy makers recognize strengths and weaknesses in EFL students' vocabulary. Based on these findings, they can develop procedures such as training both students and 
teachers to adopt certain methods that promote their vocabulary, developing a new curriculum rich in common and easy vocabulary, and to remedy the existing weakness in vocabulary.

\section{Definition of Terms}

Each of the following terms means the following in this study:

(1) Traditional method: It refers to the instructions without the aid of computers, which is often used in classroom.

(2) ICT: Information and communication technology.

(3) Online instruction games: Web sites designed for English foreign language students (EFL).

(4) Achievement: Knowledge acquired by the students during their learning of English.

(5) Games: An enjoyable activity. In the context of the current study, games are instructional tool to help students acquire second language vocabulary.

(6) Computer Assisted Instruction (CAI): Computer technologies in the instructional process to help students learn.

(7) Acquisition: The process of acquiring something new.

\section{Limitations of the Study}

The limitations of this study are stated as follows:

(1)This study is restricted to two sections of the tenth grade at Ali Khoulki Al-Sharari Secondary School for boys in Irbid the First Educational Directorate;

(2) The small sample size limits the generalization of the results finding of the study.

\section{Literature Review}

When reviewing the related literature, one finds different research investigating the use of computer games to enhance learning of new vocabulary. In the present study, the researcher reviewed studies conducted to examine the effect of computer games and research conducted to examine the effect of computer assisted language learning and the significance of computer games in enhancing the acquisition of new vocabulary among English learners in general and EFL students in particular.

To investigate the effectiveness of games on the performance of a sample of 3rd, 4th, and 5th graders, Keen (1984) designed a computer game to teach the sample of the study new vocabularies. He found that the use of the computer game was effective in enhancing the acquisition of new vocabulary among experimental group students.

Dickson (1976) used an innovative game approach to determine how to enhance first graders' recognition of sight vocabulary. The sample of the study consisted of 128 female students and 146 male students enrolling in 30 first grades in Colombia District public schools. Teachers (14) participating in the study were randomly assigned to teach three groups of students: The first used active games, the second used traditional games, and the third used passive games. The study used pre-test and post test design to compare the performance of the three groups. Multivariate analysis was used to analyze data obtained. The study concluded that there was no gender significant difference in the performance of students participating in the study. Furthermore, the study concluded that the use of traditional games was more efficient with low achieving students. In sum, the study presented concrete evidence that the use of games was a viable means for promoting new vocabulary among first graders. 
Using a sample of 22 first graders, Sudia (1985) investigated the effect of computers on the attainment of new vocabulary. Sample of the study was divided evenly into tow groups. Students in the experimental group were taught a list of words consisting of specific sight words via computer. The researcher used flash cards to teach students in the control group the same list of words. Results of the study indicated that students in the experimental group outperformed students in the control group. These students obtained higher scores as indicated post test results.

Atyyat (1992) investigated the use of Computer Assisted Instruction (CAI) on 10th graders mastering level of new English vocabulary. Sample of the study consisted of 123 students. Results of the study indicated significant difference in the acquisition of new English vocabulary between students in the experimental group and those in the control group, in favor those in the experimental group.

In their study, Reinking and Bowl (1996) designed an experiment where 6th graders read texts containing difficult words presented via a computer screen. The authors concluded that the use of computer screen was an effective means for promoting the acquisition of difficult words among 6th graders and the study recommended the use of different computer technologies to teach difficult words and enhance reading comprehension.

In their study, Lyman and Hager (1996) investigated vocabulary acquisition among intermediate students studying French. The authors used different kinds of multimedia such as computerized tests and non-computerized texts. The authors concluded that the use of multimedia was effective in promoting students' acquisition of new French words. Furthermore, the study indicated high retention level for the words taught using computerized texts.

Zimmerman (1997) investigated whether or not the instruction of a vocabulary makes a difference in students' learning of foreign languages. The study indicated that the combining of reading and communicative vocabulary instruction had significant influence on learning non-technical academic vocabulary.

To study the effect of computer-based technology on language acquisition levels of ESL (English as a Second Language) and to measure the gains in language vocabulary, Machado (1997) used a sample consisting of 200 6th, 7th, and 8th graders. The sample of the study learned English as a second language in Norwalk Mirada Unified School district. Pretests were used to measure students' writing and oral language levels. After teaching participants computers program in the instruction, post test were used to measure the effect of using computer program in the instruction process. Post test scores confirmed the hypothesis claiming that ESL students need significant support from computer-based instruction to attain second language proficiency. Students assigned in the experimental group showed significant gains in the acquisition of second language proficiency when computer-based instruction is used to teach EFL. The author recommended that language teachers need further training in computer technologies.

Uberman (1998) compared the effect of using some traditional techniques such as visual techniques, verbal explanation, and the use of dictionaries combined with the use of computer games or the attainment of new vocabularies. Results of the study revealed significant differences in the attainment levels between students taught using the traditional techniques and those taught using dictionaries combined with computer games, in favor of those in the second group. Students in the second group reported that they enjoyed the learning activities. Significant positive differences were reported by the students in the experimental group.

To study the effect of direct vocabulary instruction using computer assisted instruction on the acquisition of new vocabulary, Tozcu (1998) exposed a group of students to three hours per week via a computer technology to a list of new words. A second group of students were exposed to the same list of words using 
flashcards. Results of the study indicated significant differences in the gains of both groups for the new vocabulary, in favor of students in the experimental group.

Ayyot and Mackowick (1998) investigated the effects of different games and stimulations on communication process in the classroom. The authors also investigated the benefits of games and stimulations on the overall learning of students. The sample of the study included 251 undergraduate students enrolling in a university course in Iowa State University. The authors found that using games was an effective instructional method to teach students in the different university courses. The authors concluded that games should be designed in an organized manner and should be used to add value to the different university courses.

The Computer Assisted Language Learning (CALL) was used by Campion (1999) to study the effectiveness of this computer program on the learning and transfer of vocabulary in the age group 9-12. The study investigated the role of motivation and educational technology in the learning of EFL. Results of the study revealed that students using CALL program had significant gains in active vocabulary. The author concluded that the use of CALL was an effective means for vocabulary learning.

Using a sample of Jordanian scientific stream 11th graders, Al Madi (2002) investigated the effects of using computer assisted instruction on the achievement of this group in English. The findings of the study indicated that using computer assisted instruction had positive significant effects on the achievement of students in the experimental group, especially in their scores in the vocabulary test.

Yasin (2002) examined the effects of CAI on second graders learning in English. Findings of the study concluded that using CAI was very efficient in promoting second graders learning for English.

To compare the effects of using computer multimedia approach and the use of context based approach on the learning of English. Al-Makhzoomi and Al-Sha'r (2003) used a sample of English major university students (77). To collect data, the authors used questionnaires and pre-post tests. The sample of the study was divided into control and experimental groups. The authors used context approach materials to teach students in the control group, while they used computer multimedia to teach students in the experimental group. Findings of the study indicated that students in the experimental group significantly outperformed students in the control group. The authors recommended the need for more emphasis on the use of computer assisted multimedia to promote the instruction and learning of English among English major teachers.

Al-Salah (2004) used a computer instructional reading program to examine its effect on improving comprehension skills among secondary stage students in Jordan. The findings of the study indicated significant differences in the communication skills for students taught using computerized instructional reading program compared to students taught using traditional instruction methods.

To investigate the effects of semantic strategies based instructional program on the learning of lexical items, Zaglool (2004) used a sample of Jordanian secondary school students (384) in different public schools. Findings of the study indicated significant differences between students taught using of semantic strategies based instructional program and those taught using the traditional instructional method in the learning of lexical items.

In his study, Al-Abbadi (2005) examined the use of computer games as an instructional means on third graders' (32) attainment of higher order thinking skills. Three instructional computer games were used in the study, each covering unit in Arabic, mathematics, and science. The experimental group in the study (32) was taught using the computer games, while students in the control group were taught using traditional instruction method. Results of the study indicated significant differences in students' acquisition of the three levels of 
higher order thinking skills, in favor of experimental group students. These results suggested the positive effect of computer games on attaining higher order thinking skills.

Al-Bakrawi (2005) investigated the use of a computer ESP (English for Specific Purposes) program on the proficiency of secondary school Student Hotel stream in Jordan in English. The authors concluded that the use of ESP computer program had significant positive effects on the proficiency of study subjects in English.

The effect of using instructional software for English language grammar was investigated by Al-Qomul (2005). The author used a sample of basic stage students. The author concluded that there were significant differences in the means scores of students in the experimental group taught using CAI and those in the control group taught using traditional instruction method. The results of the study confirmed the positive effects of CAI in teaching English grammar.

Shdeifat (2006) examined the use of computer instruction games on EFL second graders' acquisition of English vocabulary. Data analysis indicated that the use of computer instruction games had significant positive effects on the learning of new vocabulary among second graders. Furthermore, students taught using computer games reported high motivation levels were more relaxed in the learning environment and stated that they benefited more when computer games were used in the instruction.

Vogel (2006) conducted a meta-analysis for the literature addressing teaching methods, games, and interactive stimulations used to teach English. The meta-analysis review indicated that the use of different computer games was the most effective instructional method reported in the literature.

Although different samples were used in the research reviewed in the current study, all studies indicated were consistent in the positive effects of using computer games in the acquisition of new vocabulary. Some of these studies had reported that the use of computer games is more effective in promoting motivation of students to learn English.

In short, these studies confirmed the positive effects of using computer games in enhancing students' acquisition from the different school levels in English and other study fields.

\section{Methods and Procedures}

This chapter presents methods and procedures used to conduct the study. First, the chapter described the population and sample; then the procedures used to establish validity and reliability of the instruments, variables of the study, data collection, and data analysis procedures, respectively.

\section{The Population of the Study}

The population of the study consisted of all tenth grade students in Irbid the First Educational Directorate in the first semester of the academic year 2008/2009 totaling 2,365 students enrolling in all schools in Irbid the First Educational Directorate totaling 80 schools according to formal records.

\section{The Sample of the Study}

From the population of the sample, the researcher selected a random and representative sample, totaling 150 students, from Ali Khoulki Secondary School in Irbid. The sample of the study was divided into two groups; one representing the experimental group ( $\mathrm{n}=75$ students) taught through computerized instructional games and the other representing the control group ( $\mathrm{n}=75$ students) taught using traditional instructional method. 


\section{Variables of the Study}

This study consistsed of the following variables:

(1) The independent variable was the method of teaching which has two sections, computerized games, and non-computerized games (Traditional method);

(2) The dependent variable was students' achievements scores on the post-test.

\section{Design of the Study}

The researcher used a quasi-experimental design. Both control and the experimental groups were given the same test before and after the study to measure differences (if any) in the achievement of students in both study groups.

\section{Instruments of the Study}

To achieve the purposes of the study, the researcher used the following instruments:

(1) An Achievement Test

After reviewing the literature focusing on measuring students' achievement in vocabulary, the researcher developed an achievement test to measure students' vocabulary before and after participating in the study. The achievement test consisted of 20 questions. Each question had four alternatives (multiple choices items) and the total score for achievement test was 20. To develop the achievement test, the researcher surfed on the Internet depending on prospective literature and previous studies, then selected a set of the most appropriate questions that measure students level in vocabulary.

Using tenth grade English textbook and after analyzing the curriculum's content in terms of vocabulary, the nature of the questions, and how they were formed, the researcher modified the test to cover all the four domains covered in the study, which were: conversation, synthesis of vocabulary, preservation, and reading skills. Accordingly, the achievement test was developed according to the content and objectives of unit one and two of tenth grade English textbook.

(2) Learning Motivation via Computer Questionnaire

To measure students' learning motivation via computers, a modified version of the questionnaire by Huwari (1996) was adopted and developed by the researcher to measure students' learning motivation via computers. The questionnaire consisted of 24 items. The first part of the questionnaire (Likert Scale) was to elicit opinions of EFL learners using the following alternatives. Each alternative is scored by giving a certain score for each alternative (Always 4, Usually 3, Sometimes 2, and Never 1). The questionnaire of this study consisted of 22 items and was used developed to elicit the opinions of EFL learners on a five point scale (Very High 5, High 4, Mid 3, Low 2, and Very Low 1).

The questionnaire was divided into four sections. The first section consisted of six items to measure study subjects' discovery skills. The second section consisted of six to measure study subjects' activity skills, while the third consisted of four items and measured students in word recognition skills. The fourth section measured study subjects' skills in paying attention during the learning process. Study subjects were instructed to complete the questionnaire and their scores on the questionnaire were summed.

(3) Computer Program

A computer program was designed to train study subjects to handle the procedures of the study. To accomplish this, Time 4 learning. Com, where students are helped to learn English as a foreign language, was used. Five training sessions were administrated for study subjects. Unit one and unit two of tenth grade English 
textbook was computerized to be used in the form of a computer game in the current study. Several words were used to cover the content of unit one and two in book ten and included the desired linguistic aspects. The content of the games was as follows: verbs, nouns, adjectives, foods, places, clothes, tools, animals, shapes, and colors.

The computer game designed in the study consisted of 10 lessons and each lesson contained 25 words, totaling 250 words. The computer game contained many tasks, e.g., listening, speaking, reading, and writing for each word. The games were based on the notion that an important part of language acquisition is to comprehend and produce a number of phrases. Moreover, there is plenty of reading in action pack and each model has one main reading focus lesson; there are also shorter reading texts and each model has between four and seven lessening texts; there is one major writing task in the writing workshop.

\section{Procedures}

The researcher used the following steps in conducting the study:

(1) The researcher used the designed games to teach the experimental group. At the same time, the class teacher used the traditional instructional method to teach students in the control group and taught the control group using the traditional method;

(2) The time limit for each lesson was 30 minutes;

(3) A warm-up activity was used to activate prior knowledge before participating in the learning activity, e.g., asking questions;

(4) The researcher assumed the role of a facilitator in the learning process by helping students complete tasks provided for them.

\section{Evaluation of Students Who Learn by Games}

To evaluate the students' learning via the computer game, a one paragraph test was administrated to students to be completed by them.

Categorize the words you learned according to the table below:

\begin{tabular}{|l|l|l|l|l|l|l|l|l|l|l|}
\hline $\mathrm{N}$ & Verbs & Nouns & Adjective & Food & Place & Clothes & Tools & Animals & Shapes & Colors \\
\hline & & & & & & & & & & \\
\hline \\
\hline
\end{tabular}




\section{Findings of the Study}

The main purpose of this Chapter is to investigate the effect of using computerized program on tenth grade students' acquisition of English vocabulary. In addition, it investigated if computer games motivate EFL learners to increase their vocabulary.

The findings are presented in light of the questions of the study. It compared the use of computerized games and the use of traditional techniques of teaching tenth grade students English vocabulary. Equivalence between experimental group and control group were ensured so that no differences were found between the study groups.

\section{Equivalence Between Groups of Study (Experiment and Control)}

To explore the equivalence between study groups (experiment and control) on pretest applied (Vocabulary achievement) and motivation instrument, means and SD were calculated for a whole test and each domains of vocabulary test and independent T-test was applied for them, Table 1 showed that:

Table 1

Result of T-test to Ensure Equivalence Between Experimental and Control Groups for Vocabulary Achievement Pretest

\begin{tabular}{|c|c|c|c|c|c|}
\hline Domains & & Mean & SDs & $\mathrm{T}$ value & Significance \\
\hline \multirow{2}{*}{ Conversation-pre } & Experimental & 2.39 & 1.23 & \multirow{2}{*}{0.132} & \multirow{2}{*}{0.985} \\
\hline & Control & 2.41 & 1.24 & & \\
\hline \multirow{2}{*}{ Construct-pre } & Experimental & 2.96 & 1.38 & \multirow{2}{*}{0.179} & \multirow{2}{*}{0.858} \\
\hline & Control & 2.92 & 1.35 & & \\
\hline \multirow{2}{*}{ Recall and Preservation-pre } & Experimental & 2.89 & 1.28 & \multirow{2}{*}{0.129} & \multirow{2}{*}{0.897} \\
\hline & Control & 2.92 & 1.25 & & \\
\hline \multirow{2}{*}{ Reading-pre } & Experimental & 3.19 & 1.16 & \multirow{2}{*}{0.069} & \multirow{2}{*}{0.945} \\
\hline & Control & 3.20 & 1.21 & & \\
\hline \multirow{2}{*}{ Vocabulary test-pre (whole) } & Experiment & 2.85 & 1.80 & \multirow{2}{*}{0.634} & \multirow{2}{*}{0.973} \\
\hline & Control & 2.86 & 1.82 & & \\
\hline
\end{tabular}

Table 1 showed the means for experimental group. As indicated, means scores for the experimental group on the vocabulary pre-test were 2.85 and for control group were 2.86 , while means for vocabulary pre test domains ranged from 2.39 to 3.19 for the experimental group and between 2.41 and 3.20 for the control group. In addition, T-test values for the equivalence between the experimental and control group for vocabulary achievement pre-test were 0.634 indicating no significant differences between control and experimental group. Furthermore, equivalence between groups of study (experimental and control) learning motivation instrument was measured by calculating means and SD for overall motivation and for each scope of the questionnaire.

The researcher believes that with more using and training with computerized program, learners become more comfortable producing vocabularies rather than just receiving it. Moreover, learning by games is a powerful aid with which learners can acquire the second language in a low anxiety setting and interesting. As a result of this study, the researcher concluded that students were more engaged in learning when they were given a chance to learn by computer games in an effective manner because they were very happy to select new words.

Results reported in the study were consistent with Leu (1988), Vasin (2000), Komal's (2005) and Al-Salah's who reported that learning via computer was an enjoyable learning activity for students in the different school subjects. 


\section{Pedagogical Implications and Recommendation for Further Research}

Based on the findings of the study, the researcher suggested the following recommendations for the Ministry of Education, teachers, instructors, and researchers.

(1) Teachers of English should have the necessary computer skills to be able to use these kinds of computer games;

(2) Textbooks must focus more on vocabulary with computers by having exercises and activities that promote and develop students' vocabulary;

(3) Training teachers and instructors in how to teach vocabulary by computerized program (games) in classrooms is an issue of high priority;

(4) It is recommended to conduct a further research focusing on new variables;

(5) Training teachers and instructors, textbooks and teaching methods participated improving and developing students learning vocabulary, further studies are needed in this area to find the exact reasons that stand for students' low level in vocabulary and to design programs which promote and improve students' vocabulary in schools.

\section{Conclusion}

Since motivation and stimulation are probably the most important factors of success in second language learning students, who were taught by using computerized games had positive attitudes towards learning via computer. The researcher believed that the results of the experimental group were invaluable. Using the computerized program (games) provides enjoyable and effective.

The researcher believed that with more using and training with computerized program, learners become more comfortable producing vocabularies rather than just receiving it. Moreover, learning by games is a powerful aid with which learners can acquire the second language in a low anxiety setting and interesting. As a result of this study, the researcher concluded that student were more engaged in learning when they were given a chance to learn by computer games in an effective manner because they were very happy to select new words .

\section{References}

AL-Abbadi, H. (2005). Effects of using computer game as an instructional tool on third grade student's acquisition of higher order thinking skills. Jordan Journal of Educational Sciences, 2, 143-148.

AL-Bakrawi, H. (2005). The effect of a computerized ESP program in Jordanian hotel stream secondary stage student's English proficiency (Unpublished doctoral dissertation, Amman Arab University for Graduate Studies, Amman, Jordan).

AL-Madi, B. (2002). The effect of using computer instruction on achievement in English of 11th scientific grade (unpublished master dissertation, Al-al-Bayt University, Mafraq, Jordan).

AL-Makzoomi, K., \& Abu AL-Sh'r, A. (2003). The effect of multimedia-computer approach and context-based approach on learning vocabulary by AL-al-Bayt University students. Al-Manarah, 10(4), 37-68.

AL-Qomul, M. (2005). The effect of using an instructional software program of English language functions on the basic stage student's achievement (Unpublished doctoral dissertation, Amman Arab University for Graduate Studies, Amman, Jordan).

AL-Salah, M. (2004). The effect of a computerized instructional reading programme on improving some comprehension skills in the secondary stage (Unpublished doctoral dissertation, Amman Arab University for Graduate Studies, Amman, Jordan).

Amory, A., \& Adams, C. (1999). The use of computer games as an educational tool. British Journal of Educational Technology, 30(4), 310-319.

Atyyat, I. (1992). The effect of computer assisted instruction upon tenth grade student's mastering of English vocabulary (Unpublished mater thesis, University of Jordan, Amman, Jordan). 
Ayotte, S., \& Mackowiak, B. (1998). Is there a place for games in the college classroom? Retrieved from http: \www.search.ebscohost.Com

Betz, J. (1995). Computer games; Increases learning in an interactive multidisciplinary environment. Journal of Educational Technology Systems, 24(4), 195-205.

Campion, R. (1999). Computer assisted foreign language learning: It's effectiveness in the primary education. Dissertation Abstracts International, 60, 217.

Coleman, D. W. (1990). Language learning through computer adventure games. Simulation \& Gaming, 21(4), 443-451.

Collin, S. (1989). The Hamlyn dictionary of computing. UK: Hamlyn.

Decure, N. (1995). Designing vocabulary games: How to use words from text. English Teaching Fourm, 31(1), 31-35.

Dickson, D. P. (1976). A comparison of the use of the active games learning medium with passive at traditional activities as a means of reinforcing recognition of selected sight vocabulary words with mid-year first grade children limited sight vocabulary (Doctoral dissertation, University of Maryland in 1970). Dissertation Abstract International, 36, 10, 64456-A.

Gardner, D. (1998). Communication games; Do we know what we are talking about? ELT Journal, 41(1), 19-24.

Hager, L., \& Davis, M. J. (1996). The case for the computer mediated reading, Une Vie de Boy. The French Review, 69(5), 775-790. Retrieved from http://www.edvisla.com

Hannafin, M. J., \& peck, K. (1988). The design development and evaluation of instructional software. New York: Macmillan Publishing Company.

Hubbard, D. (1991). Evaluating computer games for language learning. Simulation \& Gaming, 22(2), 220-224.

Huwari, K. (1996). An analysis of the evaluation procedures of writing employed by EFL teachers at the first secondary grade in Mafraq District (Unpublished A.A thesis, Yarmouk University, Irbid).

Karsilnikov, B. A. (1989). Computers and reading skills development (ERIC Document Reproduction Service, No. ED, 312, 00) Retrieved from http://www.ed.govldatabases\EricDigests

Keen, J. E. (1984). A study of the effects of games approach for spelling instruction. Dissertation Abstract International, 45, 4, 1024-A.

Kim, L. S. (1995). Creative games for the language class. English Teaching Fourm, 33(1), 35-42.

Leu (1988), Vasin (2000), Komal's (2005).

Machado, P. (1997). The effects of computer assisted technology in the language acquisition rates of second language acquisition student. Dissertation Abstract international, 58, 1254.

Mumtaz, S. (2001). Children enjoyment and perception of computer use in the home and the school. Computers \& Education, 36, 347-362.

Nagy, W. E. (1989). Vocabulary instruction and reading comprehension. In Eric Digest, 4 Bloomington, Indiana: ERIC Clearinghouse on Reading English, and Communication.

Paz, S. (1993). The dramatic game and the conversational act. International Journal of Instructional Media, 31(2), 18-21.

Reinking, D., \& Bowl, L. B. (1996). Computers in reading and writing (Vol. 2). Mahwah: Lawrence Erlbaum Associates Publishers.

Shdaifat, M. (2006). The effect of using computerized instructional games on EFL second grade pupils learning of vocabulary (B.A. English field teacher, Yarmouk University, Irbid-Jordan).

Shelley, V. (2006). 5 top reasons to teach children English with fun ESL games. Retrieved from http://www.search.ebscohost.Com

Soloway, E. (1998). No one is making money in educational software. Communication of the ACM, 41(2), 11-15.

Sudia, D. (1985). The computer's effect on the learning of new words (Master thesis, Kean College of New Jersey).

Teacher's Magazine, Ministry of Education. (2007).

Tozcu, A. (1998). The effect of teaching sight vocabulary with computer assisted instruction on vocabulary gain decrease in reaction time for frequent word recognition, and reading comprehension. Dissertation Abstract International, 59, 1144.

Uberman, A. (1998). The use of games for vocabulary and revision presentation. English Teaching Forum, 36(1), 20-28.

Vogel, J. J. (2006). Computer games and interactive simulations for learning: A meta-analysis study. Dissertation Abstract International, DAI-A 58107, 2136.

Ward, P. A. (1987). A comparison of computer assisted traditional drill and practice on elementary students, vocabulary knowledge and attitude toward reading instruction. Dissertation Abstract International, 47(8), 2977-2978.

Wishart, J., \& Blease, D. (1989). Cognitive factors related user environment with computers and there effects upon learning from an educational-computer game (pp. 167-177). Computers and Education, 15(2), 1-3. 
Yasin, I. (2002). The effect of computer-a assisted instruction on second grade pupil's learning of English in Bany Kinanah district of education (Unpublished master thesis, Yarmouk University, Irbid, Jordan).

Zagllool, Z. (2004). The effect of an instructional programme based on semantic strategies on the learning of lexical items by secondary stage students (Unpublished doctoral dissertation, Amman Arab University for Graduate Studies, Amman, Jordan).

Zimmerman, E. B. (1997). Do reading and interactive vocabulary instruction make a difference? An empirical study. TESOL QUARTEELY, 31(1), 121-1450. 